\title{
Using a mixture of local bone dust and morselized bone as graft materials in single- and double-level ACDF
}

Fei Ma ${ }^{1,2 \dagger}$, Shicai $\mathrm{Xu}^{1,2+}$, Yehui Liao ${ }^{1,2}$, Qiang Tang ${ }^{1,2}$, Chao Tang ${ }^{1,2}$, Qing Wang ${ }^{1,2}$ and Dejun Zhong ${ }^{1,2^{*}}$

\begin{abstract}
Background: Using a cage filled with local bone in anterior cervical discectomy and fusion (ACDF) can eliminate morbidities associated with autograft harvest from the iliac crest while achieving high fusion rates. However, there is still no consensus regarding the methods for using local bone grafts. This retrospective study was performed to compare the clinical and radiological outcomes of using a mixture of bone dust and morselized bone versus morselized bone alone in ACDF.
\end{abstract}

Methods: A retrospective study of 228 patients affected by cervical degenerative disease who had undergone single- or double-level ACDF between January 2014 and June 2018 was performed. Nanohydroxyapatite/ polyamide-66 (n-HA/PA66) combined with morselized bone was used in 111 patients (group A: single-level ACDF in 51 patients and double-level ACDF in 60 patients), whereas the n-HA/PA66 cage combined with a mixture of bone dust and morselized bone was used in 117 patients (group B: single-level ACDF in 58 patients and double-level ACDF in 59 patients). The fusion rate, extent of cage subsidence, fusion segmental height (FSH), C2-7 lordosis, segmental sagittal alignment (SSA), 10-point visual analog scale (VAS) score, and Neck Disability Index (NDI) were compared between the two groups.

Results: The VAS score and NDI were significantly reduced after the operation in group A and group B. At the final follow-up, the fusion rate was $90.2 \%(46 / 51)$ and $94.8 \%$ (55/58) in patients treated with single-level ACDF in group $A$ and group B, respectively $(p>0.05)$. In patients treated with double-level ACDF, bone fusion was achieved in 52 patients (86.7\%) in group A and 55 patients $(93.2 \%)$ in group B $(p>0.05)$. The fusion rate of single- and doublelevel ACDF was higher in patients in group $B$ than those in group $A$ at the 3-month, 6-month and 12-month follow-ups $(p<0.05)$. The extent of cage subsidence after single- and double-level ACDF was lower in patients in group B $(1.5 \pm 0.5 \mathrm{~mm}$ and $2.3 \pm 0.8 \mathrm{~mm}$, respectively) than in those in group A $(1.8 \pm 0.7 \mathrm{~mm}$ and $2.9 \pm 1.4 \mathrm{~mm}$, respectively) $(p<0.05)$. There was no significant difference between the two groups in the C2-7 lordosis, FSH, SSA, VAS score, or NDI before or after the operation ( $p>0.05)$.

\footnotetext{
* Correspondence: zdj_1974@163.com

${ }^{\dagger}$ Fei Ma and Shicai Xu contributed equally to this work

${ }^{\dagger}$ Fei Ma and Shicai Xu are co-first authors.

'Department of Orthopedics, Affiliated Hospital of Southwest Medical

University, No. 25 Taiping Street, Sichuan 646000 Luzhou, China

${ }^{2}$ Sichuan Provincial Laboratory of Orthopedic Engineering, No. 25 Taiping

Street, Sichuan 646000 Luzhou, China
}

(c) The Author(s). 2021 Open Access This article is licensed under a Creative Commons Attribution 4.0 International License, which permits use, sharing, adaptation, distribution and reproduction in any medium or format, as long as you give appropriate credit to the original author(s) and the source, provide a link to the Creative Commons licence, and indicate if changes were made. The images or other third party material in this article are included in the article's Creative Commons. licence, unless indicated otherwise in a credit line to the material. If material is not included in the article's Creative Commons licence and your intended use is not permitted by statutory regulation or exceeds the permitted use, you will need to obtain permission directly from the copyright holder. To view a copy of this licence, visit http://creativecommons.org/licenses/by/4.0/ The Creative Commons Public Domain Dedication waiver (http://creativecommons.org/publicdomain/zero/1.0/) applies to the data made available in this article, unless otherwise stated in a credit line to the data. 
Conclusions: Using a mixture of local bone dust and morselized bone as cage-filling materials yielded comparably good clinical outcomes as using morselized bone alone in single- and double-level ACDF. However, the mixture graft of bone dust and morselized bone was more beneficial in promoting early fusion and reducing cage subsidence.

Keywords: Anterior cervical discectomy and fusion, Bone dust, Morselized bone, Graft materials, Surgery

\section{Introduction}

Anterior cervical discectomy and fusion (ACDF), which has been practiced for over 60 years, is a classic surgical technique widely used to treat cervical myelopathy or radiculopathy $[1,2]$. ACDF enables the removal of compressive anterior lesions, such as osteophytes and intervertebral discs, and the restoration of cervical spinal alignment and stability [3]. Graft materials, such as implanted cages, allografts, or autografts, should be inserted in the disc space to achieve intervertebral space support and union after removal of the disc and osteophytes [4]. Iliac bone autografts are the traditional gold standard in ACDF to achieve solid fusion. However, the graft harvesting procedure can result in a range of complications, namely, donor-site pain, hematoma, and infection [5-7].

Implanted cages, including titanium mesh cages, polyetheretherketone (PEEK) cages, and nanohydroxyapatite/ polyamide66 (n-HA/PA66) cages, filled with local bone, have popularly been used as ideal and effective graft materials to avoid donor-site morbidities after iliac bone autografting during $\mathrm{ACDF}$ and posterior lumbar fusion [8-12]. Morselized bone obtained from removing osteophytes using a punch or curette has reportedly been used as a graft material in ACDF [8-10]. However, the bone dust (or bone shavings) obtained from removing osteophytes using a high-speed burr is often discarded without being used during ACDF.

This retrospective study was performed to explore whether using a mixture of local bone dust and morselized bone as n-HA/PA66 cage-filling materials will be more beneficial in terms of radiographic and clinical outcomes than using morselized bone alone during ACDF.

\section{Methods}

Ethics approval was obtained before this retrospective study was initiated. Informed consent was also obtained from all subjects. In this study, all methods were performed in accordance with the relevant guidelines and regulations.

\section{Clinical data}

Consecutive patients with degenerative cervical disease who underwent single- or double-level ACDF from January 2014 to June 2018 were included in this study. All patients underwent and were nonresponsive to conservative treatment before the operation. All operations were performed by a single surgeon (D.J.Z.). The involved segments were between C3 and C7. Patients who underwent surgery due to an infection, trauma, or tumor were excluded. Patients with a history of anterior or posterior surgical procedures, a follow-up period $<24$ months, or a lack of sufficient radiographic and clinical data were also excluded. Ultimately, 228 patients were included in this retrospective study. Preoperative anteroposterior radiography, lateral radiography, flexion-extension lateral radiography, three-dimensional computed tomography (CT), and magnetic resonance imaging (MRI) of the cervical spine were performed in all patients. One hundred and eleven patients who underwent surgery between January 2014 and June 2016 were included in group A, in which local morselized bone was used as an n-HA/PA66 cagefilling material during ACDF. One hundred and seventeen patients who underwent ACDF between July 2016 and January 2018 were included in group B, in which the nHA/PA66 cage was filled with a mixture of local bone dust and morselized bone.

\section{Surgical procedure and postoperative management}

After general anesthesia was established, the patient was placed in the supine position. A modified right-side Smith-Robinson technique was applied in all patients [1]. After part of the disc material was removed, the vertebral body's anterior lip was removed using a Kerrison punch, and the local morselized bone was collected. The remaining disc material and cartilage endplate were completely removed with a curette. In group A, the posterior osteophytes were removed using a Kerrison punch, highspeed burr, or/and curette. The superior and inferior bone endplates were carefully flattened using a burr. When the bone endplate seeped blood, abrading was stopped to avoid postoperative cage subsidence caused by excessive destruction of the bone endplate. After the disc height was measured, an appropriate n-HA/PA66 cage filled with local morselized bone was implanted into the disc space. An anterior cervical plate was later used to achieve immediate stabilization. In group B, the posterior osteophytes were abraded using a stainless steel burr, and the bone dust was harvested by scooping with a curette.

The difference between group A and group B was that the posterior osteophytes in group B were abraded using a high-speed burr, and the bone dust was harvested by scooping with a curette. Then, the n-HA/PA66 cage was filled with a mixture of bone dust and morselized bone in group B (Fig. 1). 


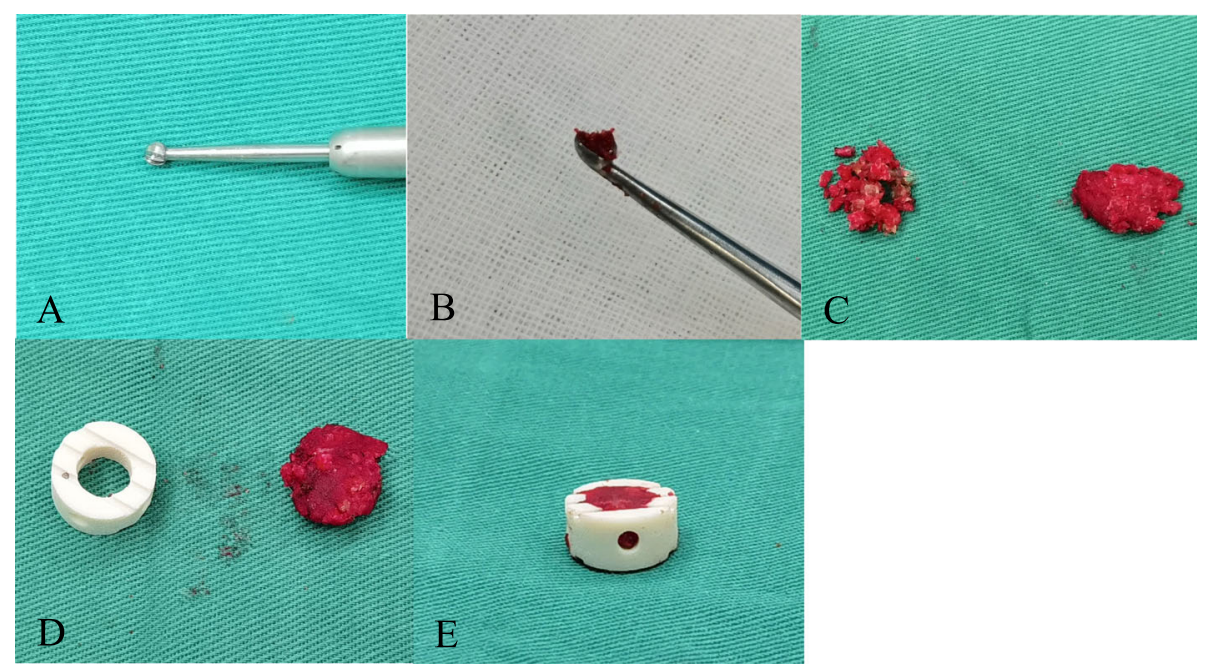

Fig. 1 A mixture of bone dust and morselized bone was used as an n-HA/PA66 cage-filling material during the operation. A, B Posterior osteophytes were abraded using a stainless steel burr, and bone dust was harvested by scooping with a curette. C Morselized bone and bone dust. D An n-HA PA66 cage and the bone mixture. E An n-HA/PA66 cage filled with the bone mixture

A suction drain was inserted and then removed 1 or 2 days after the operation in all patients in these two groups. All patients wore a postoperative soft cervical collar for 6-12 weeks.

\section{Evaluation parameters and follow-up}

The operative duration, blood loss, and complications were recorded and compared between the two groups. The Neck Disability Index (NDI) and the 10-point visual analog scale (VAS) score were used to assess the clinical outcomes. The Kellgren grading system [13] was used to evaluate degeneration of the surgical segments preoperatively.

A cervical spine $\mathrm{X}$-ray, which was used to evaluate the fusion segmental height (FSH), segmental sagittal alignment (SSA), and C2-7 lordosis, was performed two days postoperatively, one year postoperatively, and at the final follow-up. The FSH was defined as the distance between the midpoints of the superior endplate of the cephalic vertebra and the inferior endplate of the caudal vertebra of the fused segments. The extent of subsidence was defined as the difference in the FSH between postoperatively and the final follow-up. A subsidence distance $>2 \mathrm{~mm}$ and $>3 \mathrm{~mm}$ was considered to indicate radiographic subsidence in patients treated with single-level and double-level ACDF, respectively. The SSA was defined as the angle between the line along the superior endplate of the cephalad adjacent level and the line along the inferior endplate of the caudal adjacent level. The $\mathrm{C} 2-7$ lordosis was defined as the sagittal Cobb angle of C2-7, and we defined lordotic angles as positive angles and kyphotic angles as negative angles. Two spinal surgeons measured all of these radiographic parameters, and the average value for each was adopted for analysis. The fusion status was evaluated by X-ray examination at three and six months after surgery. Fusion was judged by the absence of motion between the spinous processes on flexion-extension lateral radiographs, the absence of a radiolucent gap between the cage and endplate, and the presence of continuous bridging bone trabeculae at the cage-endplate junction. A three-dimensional CT scan was obtained for evaluation of the fusion status based on the fivegrade criteria established by Brantigan et al. [14] at one year after surgery and the final follow-up. Grades 4 and 5 were defined as indicating bone fusion. In the evaluation and statistical analysis of fusion, patients treated with double-level ACDF were divided into three categories: no fusion (no fusion in either segment); one-level fusion (fusion in one of the segments); and two-level fusion (fusion in both segments).

\section{Statistical analysis}

The statistical evaluation was performed using SPSS 22.0 (IBM Corp., Armonk, NY, USA). Patients treated with single-level and double-level ACDF were compared separately between the two groups. Quantitative data are presented as the mean \pm standard deviation (SD). The independent t-test and the chi-square test or Fisher's test was applied to compare the pre- and postoperative radiological and clinical data of the two groups. Paired ttests were used for intragroup comparisons. A $p$-value of $<0.05$ was considered statistically significant. 


\section{Results}

\section{General outcomes}

There was no significant difference in age, sex, operative segment, Kellgren grade of the operative segment, medical diseases (diabetes, hypertension), smoking, operative duration, blood loss, or follow-up time between the two groups of patients treated with single- or double-level ACDF (all p>0.05). In patients treated with single- or double-level ACDF in group A and group B, the NDI and VAS score for neck and arm pain were significantly decreased after the operation $(p<0.05)$. There was no significant difference in the NDI or VAS score between the two groups of patients treated with single- or double-level ACDF before or after the operation $(p>0.05)$. Clinical outcomes are shown in Tables 1 and 2 .

Table 1 Patient demographic data in single-level ACDF

\begin{tabular}{|c|c|c|c|}
\hline Variables & Group A $(n=51)$ & Group B $(n=58)$ & $P$ value \\
\hline Age (year) & $48.1 \pm 7.2$ & $48.7 \pm 8.5$ & 0.73 \\
\hline Male gender & $21 / 30$ & $29 / 29$ & 0.36 \\
\hline Hypertension & $8 / 51$ & $7 / 58$ & 0.58 \\
\hline Diabetes & $4 / 51$ & $6 / 58$ & 0.91 \\
\hline Smoker & $11 / 51$ & $9 / 58$ & 0.45 \\
\hline Follow-up (month) & $36.7 \pm 11.3$ & $34.8 \pm 6.2$ & 0.27 \\
\hline Segements & & & 0.10 \\
\hline $\mathrm{C} 3 / \mathrm{C} 4$ & 8 & 3 & \\
\hline $\mathrm{C} 4 / \mathrm{C} 5$ & 9 & 13 & \\
\hline $\mathrm{C} 5 / \mathrm{C6}$ & 18 & 30 & \\
\hline $\mathrm{C} 6 / \mathrm{C7}$ & 16 & 12 & \\
\hline Kellgren Grading Standards & & & 0.74 \\
\hline 0 & 4 & 3 & \\
\hline 1 & 4 & 8 & \\
\hline 2 & 12 & 15 & \\
\hline 3 & 23 & 21 & \\
\hline 4 & 8 & 11 & \\
\hline Operative time (min) & $79.5 \pm 20.6$ & $74.7 \pm 18.5$ & 0.20 \\
\hline Blood loss (ml) & $62.4 \pm 36.9$ & $56.8 \pm 31.5$ & 0.40 \\
\hline Complications & $1 / 51$ & $1 / 58$ & 1.00 \\
\hline \multicolumn{4}{|l|}{ Neck VAS (point) } \\
\hline Preoperative & $5.4 \pm 2.2$ & $4.9 \pm 1.8$ & 0.20 \\
\hline Postoperative & $3.1 \pm 1.9^{*}$ & $2.7 \pm 2.0^{*}$ & 0.29 \\
\hline 1 year follow-up & $2.3 \pm 1.4^{*}$ & $2.1 \pm 1.3^{*}$ & 0.44 \\
\hline Final follow-up & $1.5 \pm 0.8^{*}$ & $1.6 \pm 1.0^{*}$ & 0.57 \\
\hline \multicolumn{4}{|l|}{ Arm VAS (point) } \\
\hline Preoperative & $5.9 \pm 2.1$ & $6.2 \pm 2.0$ & 0.45 \\
\hline Postoperative & $3.4 \pm 1.8^{*}$ & $3.2 \pm 1.6^{*}$ & 0.54 \\
\hline 1 year follow-up & $2.0 \pm 1.1^{*}$ & $2.2 \pm 1.4^{*}$ & 0.41 \\
\hline Final follow-up & $1.7 \pm 1.0^{*}$ & $1.5 \pm 0.8^{*}$ & 0.25 \\
\hline \multicolumn{4}{|l|}{ NDI } \\
\hline Preoperative & $31.2 \pm 13.8$ & $29.8 \pm 11.4$ & 0.56 \\
\hline 6 months follow-up & $17.8 \pm 12.4^{*}$ & $15.7 \pm 11.2^{*}$ & 0.36 \\
\hline Final follow-up & $10.3 \pm 6.1^{*}$ & $9.7 \pm 7.3^{*}$ & 0.65 \\
\hline
\end{tabular}

VAS 10-point visual analog scale, NDI Neck Disability Index

* Compared with preoperative $(P<0.05)$ 
Table 2 Patient demographic data in double-level ACDF

\begin{tabular}{|c|c|c|c|}
\hline Variables & Group A $(n=60)$ & Group B $(n=59)$ & $P$ value \\
\hline Age (year) & $51.9 \pm 9.0$ & $53.8 \pm 9.9$ & 0.27 \\
\hline Male Gender & $27 / 33$ & $25 / 34$ & 0.92 \\
\hline Hypertension & $12 / 60$ & $9 / 59$ & 0.50 \\
\hline Diabetes & $6 / 60$ & $8 / 59$ & 0.55 \\
\hline Smoker & $16 / 60$ & $12 / 59$ & 0.42 \\
\hline Follow-up (month) & $38.4 \pm 13.6$ & $35.1 \pm 7.9$ & 0.11 \\
\hline Segements & & & 0.52 \\
\hline $\mathrm{C} 3-\mathrm{C} 5$ & 5 & 2 & \\
\hline C4-C6 & 27 & 28 & \\
\hline $\mathrm{C} 5-\mathrm{C} 7$ & 28 & 29 & \\
\hline Kellgren Grading Standards & & & 0.76 \\
\hline 0 & 7 & 5 & \\
\hline 1 & 11 & 13 & \\
\hline 2 & 37 & 34 & \\
\hline 3 & 51 & 46 & \\
\hline 4 & 14 & 20 & \\
\hline Operative time (min) & $110.8 \pm 24.2$ & $102.7 \pm 29.5$ & 0.10 \\
\hline Blood loss (ml) & $93.8 \pm 42.1$ & $88.5 \pm 37.4$ & 0.47 \\
\hline Complications & $2 / 60$ & $1 / 59$ & 1.00 \\
\hline \multicolumn{4}{|l|}{ Neck VAS (point) } \\
\hline Preoperative & $5.7 \pm 2.0$ & $5.3 \pm 2.1$ & 0.29 \\
\hline Postoperative & $3.4 \pm 1.7^{*}$ & $3.1 \pm 1.8^{*}$ & 0.54 \\
\hline 1 year follow-up & $2.6 \pm 1.5^{*}$ & $2.5 \pm 1.6^{*}$ & 0.81 \\
\hline Final follow-up & $1.9 \pm 1.0^{*}$ & $2.0 \pm 0.9^{*}$ & 0.57 \\
\hline \multicolumn{4}{|l|}{ Arm VAS (point) } \\
\hline Preoperative & $6.4 \pm 1.9$ & $6.7 \pm 1.8$ & 0.38 \\
\hline Postoperative & $3.3 \pm 1.6^{*}$ & $3.1 \pm 1.5^{*}$ & 0.48 \\
\hline 1 year follow-up & $2.1 \pm 1.2^{*}$ & $1.9 \pm 1.1^{*}$ & 0.35 \\
\hline Final follow-up & $1.8 \pm 0.6^{*}$ & $1.7 \pm 0.7^{*}$ & 0.40 \\
\hline \multicolumn{4}{|l|}{ NDI } \\
\hline Preoperative & $29.9 \pm 13.1$ & $32.4 \pm 12.3$ & 0.29 \\
\hline 6 months follow-up & $15.9 \pm 10.1^{*}$ & $17.2 \pm 11.5^{*}$ & 0.51 \\
\hline Final follow-up & $11.2 \pm 7.4^{*}$ & $10.5 \pm 6.9^{*}$ & 0.60 \\
\hline
\end{tabular}

VAS 10-point visual analog scale, NDI Neck Disability Index

* Compared with preoperative $(P<0.05)$

\section{Radiological outcomes \\ Single-level ACDF group}

There was no significant difference in the FSH, SSA, or C2-7 lordosis between the two groups preoperatively, two days postoperatively, one year postoperatively, or at the final follow-up. At the final follow-up, the subsidence distance in group A was $1.8 \pm 0.7 \mathrm{~mm}$, which was significantly higher than the distance of $1.5 \pm 0.5 \mathrm{~mm}$ observed in group $\mathrm{B}(p=0.011)$. The radiographic rate of subsidence in patients in group A was slightly higher than that of patients in group B, but there was no significant difference $(p=0.057)$. The bone fusion rate in group $\mathrm{B}$ was better than that in group A at 3 months (11.8\% VS. $29.3 \% ; p=0.025), 6$ months (31.4\% VS. $53.4 \% ; p=0.020$ ) and one year (76.5\% VS. 91.4\%; $p=0.032)$ after the operation, and without a significant difference at the final follow-up (90.2\% VS. 94.8\%; $p=0.577$ ) (Fig. 2). Radiological outcomes are shown in Table 3.

\section{Double-level ACDF group}

There was no significant difference in the FSH, SSA, or C2-7 lordosis between the two groups before or after the 


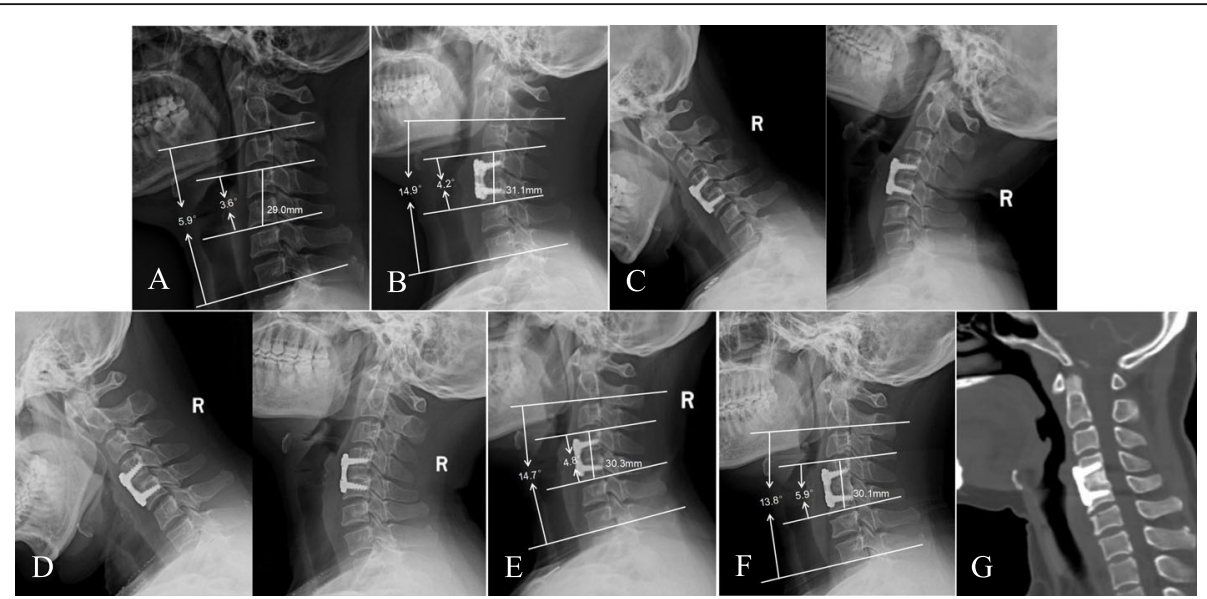

Fig. 2 A 48-year-old female patient underwent single-level ACDF due to C4/5 disc herniation. A mixture of bone dust and morselized bone was used as an n-HA/PA66 cage-filling material during the operation. A Preoperative lateral radiograph of the cervical spine showing narrowing of the C4/5 disC space. B Postoperative lateral radiograph showing that the n-HA/PA66 cage increased the FSH, SSA, and C2-7 lordotic angle. C, D Flexion-extension lateral radiographs showing fusion at the 3-month and 6-month follow-ups. $\mathbf{E}, \mathbf{F}$ Lateral radiographs showing mild cage subsidence at the 1-year and final follow-ups; the FSH, SSA, and C2-7 lordotic angle remained stable. G Three-dimensional CT at the 28-month follow-up time showing grade 5 fusion

operation (all $p>0.05$ ). At the final follow-up, the subsidence distance in group A was $2.9 \pm 1.4 \mathrm{~mm}$, which was slightly higher than the distance of $2.3 \pm 0.8 \mathrm{~mm}$ in group B $(p=0.005)$. There was no significant difference in the radiographic subsidence rate between the two groups $(p=0.138)$. The total bone fusion rate in group B was better than that in group A at 3 months $(p=0.033)$, 6 months $(p=0.014)$ and one year $(p=0.048)$ after the operation, and there was no significant difference at the final follow-up ( $p=0.455)$ (Fig. 3). Radiological outcomes are shown in Table 4.

\section{Complications}

One patient treated with double-level ACDF in group A developed a postoperative wound infection. A subcutaneous hematoma occurred in 1 patient treated with doublelevel ACDF in group B. Only one patient treated with single-level ACDF in group A underwent revision surgery because of adjacent segment degeneration 40 months after the initial ACDF procedure. All complications were resolved after the corresponding treatment. There was 1 case of screw breakage in both group A and group B, but satisfactory fusion was achieved. There were no cases of plate displacement, cage displacement, major neurological complications, or pseudarthrosis formation in either group.

\section{Discussion}

Artificial cages filled with additional fusion materials, such as autologous iliac bone, local bone, demineralized bone matrix (DBM), bone matrix protein (BMP), or allografts, have been widely used in ACDF [6, 10, 15-17]. The use of local bone as a cage-filling material can avoid donor-site complications, including pain, hematoma, and infection, caused by using iliac bone autografts $[8-10,18]$. The risk of disease transmission and the additional costs of using DBM or allografts can also be prevented [10]. Local bone is also more convenient to obtain than an iliac bone graft during surgery. Many studies have confirmed the efficacy of using local morselized bone as an artificial cage-filling material in ACDF [8-10]. A long-term follow-up study conducted by $\mathrm{Hu}$ et al. [8] showed that both of a PEEK cage and an n-HA/PA66 cage combined with local morselized bone in single-level ACDF yielded excellent radiographic and clinical outcomes, with a fusion rate as high as $98 \%$. Liu et al. [9] reported similar fusion rates for a local morselized bone graft to fill a PEEK cage compared with an autologous tricortical iliac bone graft.

In our study, patients in group A were treated with an n-HA/PA66 cage filled with morselized bone in singleor double-level ACDF. The mean NDI and VAS score were significantly improved after compared with before the operation. The mean SSA and $\mathrm{C} 2-7$ lordotic angle increased more than $2^{\circ}$ after both single- and doublelevel ACDF. The bone fusion rate was $90.2 \%$ at the final follow-up in patients treated with single-level ACDF and $86.7 \%$ in patients treated with double-level ACDF. The clinical efficacy and radiographic results were satisfactory and similar to those in previous reports. However, the early solid fusion rate was relatively low, and the subsidence rate was still higher than $20 \%$ in single- and double-level ACDF. Previously, bone dust harvested using a high-speed drill was reported to have therapeutic potential as an autologous adjunct to aid osseous fusion 
Table 3 Radiographic outcomes in single-level ACDF

\begin{tabular}{|c|c|c|c|}
\hline Variables & Group A $(n=51)$ & Group B $(n=58)$ & $P$ value \\
\hline \multicolumn{4}{|l|}{ Fusion rate } \\
\hline 3 months follow-up & $6 / 51$ & $16 / 58$ & 0.03 \\
\hline 6 months follow-up & $16 / 51$ & $31 / 58$ & 0.02 \\
\hline 1 year follow-up & $39 / 51$ & $53 / 58$ & 0.03 \\
\hline Final follow-up & $46 / 51$ & $55 / 58$ & 0.58 \\
\hline \multicolumn{4}{|l|}{ FSH (mm) } \\
\hline Preoperative & $30.7 \pm 3.2$ & $29.8 \pm 3.0$ & 0.13 \\
\hline Postoperative & $33.2 \pm 3.4$ & $32.4 \pm 3.2$ & 0.21 \\
\hline 1 year follow-up & $31.9 \pm 2.9$ & $31.2 \pm 2.7$ & 0.19 \\
\hline Final follow-up & $31.4 \pm 2.8$ & $30.9 \pm 2.7$ & 0.35 \\
\hline Subsidence (mm) & $1.8 \pm 0.7$ & $1.5 \pm 0.5$ & 0.01 \\
\hline Subsidence rate & $11 / 51$ & $5 / 58$ & 0.06 \\
\hline \multicolumn{4}{|l|}{ C2-7 lordosis $\left(^{\circ}\right)$} \\
\hline Preoperative & $10.7 \pm 6.7$ & $11.5 \pm 8.1$ & 0.57 \\
\hline Postoperative & $14.3 \pm 6.7$ & $15.5 \pm 8.6$ & 0.39 \\
\hline 1 year follow-up & $13.9 \pm 7.3$ & $15.3 \pm 8.4$ & 0.36 \\
\hline Final follow-up & $13.1 \pm 8.1$ & $14.8 \pm 9.2$ & 0.31 \\
\hline \multicolumn{4}{|l|}{ SSA $\left(^{\circ}\right)$} \\
\hline Preoperative & $2.1 \pm 4.8$ & $2.7 \pm 5.5$ & 0.55 \\
\hline Postoperative & $7.2 \pm 3.4$ & $8.1 \pm 4.9$ & 0.27 \\
\hline 1 year follow-up & $5.4 \pm 3.1$ & $6.7 \pm 4.6$ & 0.09 \\
\hline Final follow-up & $5.1 \pm 3.5$ & $6.4 \pm 4.0$ & 0.08 \\
\hline
\end{tabular}

[19]. Histological analysis of bone dust collected during spinal surgeries has confirmed the presence of viable osteocytes in the bone dust $[19,20]$. An in vitro study conducted by Eder et al. [21] revealed that bone shavings (bone dust) harvested using a high-speed burr had osteogenic potential, but this potential was lower than that of laminectomy bone chips (morselized bone) obtained using a Kerrington rongeur. In 2005, Shad et al. [22] reported the use of bone dust alone to fill the cage in ACDF. In their study, the clinical outcomes were relatively good, but the solid bone fusion rate was $77.3 \%$ $(17 / 22)$ at the one-year follow-up. This result indicates that using bone dust alone to fill the cage is not sufficient to achieve an excellent bone fusion rate at the early stage after the operation. The use of bone dust, however, provides a resource for augmenting local autografts during spinal fusion and is not associated with any significant cost or effort [20].

To further optimize the method of performing ACDF, we used a high-speed burr to abrade the posterior osteophytes and harvested the bone dust by scooping with a curette in patients in group B. During the surgery, the bone dust and morselized bone were mixed and later used to fill the n-HA/PA66 cage. In our opinion, using a mixture of bone dust and morselized bone to fill a cage is similar to filling a container with small stones and sand. In this way, the tiny space between the morselized bone can be fully filled by the bone dust, and the volume of autogenous bone in the cage can be increased. The contact area between the autogenous bone and the endplate is also more extensive than that achieved using morselized bone alone to fill the cage, facilitating the

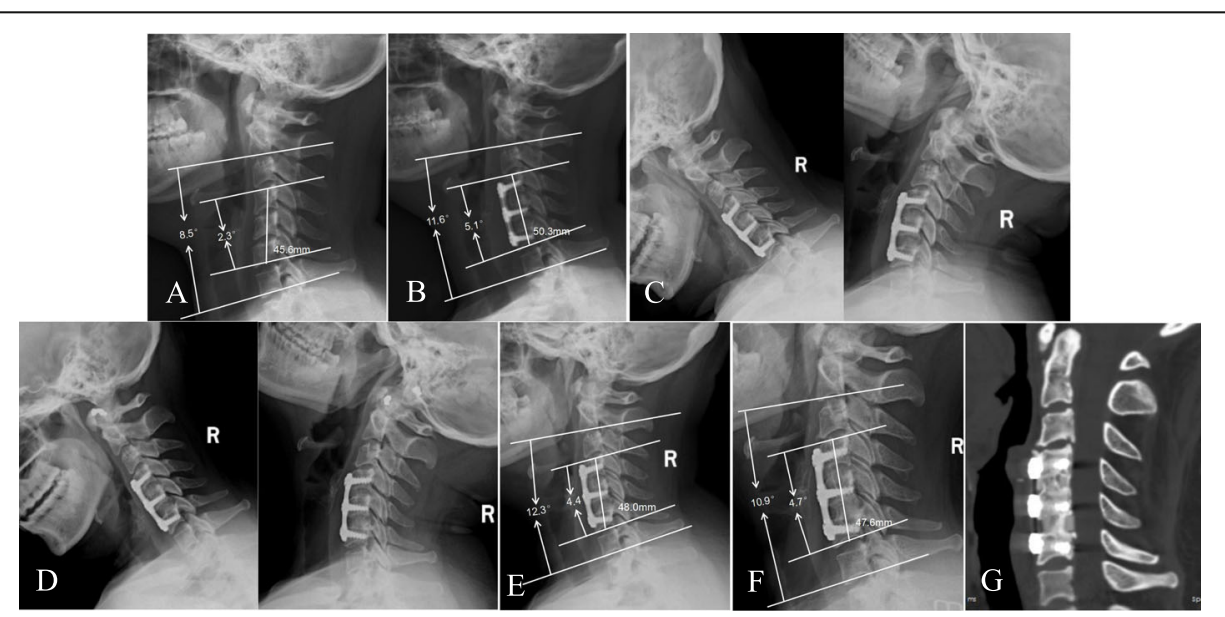

Fig. 3 A 50-year-old female patient underwent double-level ACDF due to cervical myelopathy. A mixture of bone dust and morselized bone was used as an n-HA/PA66 cage-filling material in this patient. A Preoperative lateral radiograph of the cervical spine showing narrowing of the C4/5 and C5/6 disc spaces. B Postoperative lateral radiograph showing that the n-HA/PA66 cage increased the FSH, SSA, and C2-7 lordotic angle. C Three-month follow-up flexion-extension lateral radiograph showing the absence of motion between the spinous processes. D Six-month followup flexion-extension lateral radiograph showing solid fusion. E, F One-year and final follow-up lateral radiographs showing mild cage subsidence in both segments; the FSH, SSA, and C2-7 lordotic angle remained stable. G Three-dimensional CT at the 36-month follow-up time showing grade 5 fusion in both segments 
Table 4 Radiographic outcomes in double-level ACDF

\begin{tabular}{|c|c|c|c|}
\hline Variables & Group A $(n=60)$ & Group B $(n=59)$ & $P$ value \\
\hline \multicolumn{4}{|l|}{ Fusion rate } \\
\hline 3 months follow-up & & & 0.03 \\
\hline No fusion & 53 & 39 & \\
\hline One-level fusion & 4 & 9 & \\
\hline Two-level fusion & 3 & 11 & \\
\hline 6 months follow-up & & & 0.01 \\
\hline No fusion & 37 & 21 & \\
\hline One-level fusion & 11 & 15 & \\
\hline Two-level fusion & 12 & 23 & \\
\hline 1 year follow-up & & & 0.048 \\
\hline No fusion & 15 & 6 & \\
\hline One-level fusion & 20 & 17 & \\
\hline Two-level fusion & 25 & 36 & \\
\hline Final follow-up & & & 0.46 \\
\hline No fusion & 3 & 1 & \\
\hline One-level fusion & 5 & 3 & \\
\hline Two-level fusion & 52 & 55 & \\
\hline \multicolumn{4}{|l|}{ FSH (mm) } \\
\hline Preoperative & $49.1 \pm 4.5$ & $48.9 \pm 4.2$ & 0.80 \\
\hline Postoperative & $53.4 \pm 4.9$ & $52.7 \pm 4.0$ & 0.40 \\
\hline 1 year follow-up & $51.2 \pm 4.1$ & $51.0 \pm 3.7$ & 0.78 \\
\hline Final follow-up & $50.5 \pm 3.8$ & $50.4 \pm 3.6$ & 0.88 \\
\hline Subsidence (mm) & $2.9 \pm 1.4$ & $2.3 \pm 0.8$ & 0.01 \\
\hline Subsidence rate & $17 / 60$ & $10 / 59$ & 0.14 \\
\hline \multicolumn{4}{|l|}{ C2-7 lordosis $\left(^{\circ}\right)$} \\
\hline Preoperative & $12.9 \pm 10.8$ & $11.0 \pm 12.4$ & 0.37 \\
\hline Postoperative & $19.1 \pm 11.5$ & $18.4 \pm 11.9$ & 0.75 \\
\hline 1 year follow-up & $17.3 \pm 13.4$ & $16.9 \pm 12.7$ & 0.87 \\
\hline Final follow-up & $15.4 \pm 10.8$ & $17.2 \pm 12.4$ & 0.40 \\
\hline \multicolumn{4}{|l|}{ SSA $\left(^{\circ}\right)$} \\
\hline Preoperative & $4.2 \pm 5.4$ & $3.9 \pm 6.1$ & 0.78 \\
\hline Postoperative & $10.7 \pm 6.1$ & $9.3 \pm 7.0$ & 0.26 \\
\hline 1 year follow-up & $9.2 \pm 5.3$ & $8.6 \pm 6.5$ & 0.58 \\
\hline Final follow-up & $8.5 \pm 4.9$ & $8.2 \pm 5.7$ & 0.76 \\
\hline
\end{tabular}

FSH Fusion segmental height, SSA Segmental sagittal alignment

growth of blood vessels into the graft. The bone grafts are simultaneously resorbed as new bone deposition occurs within the graft site [23, 24]. Animal experiments have shown that the resorption of bone dust is faster than that of morselized bone [25]. We used a mixture of bone dust and morselized bone to fill the cage in patients in group B. This method not only controls bone absorption but also promotes bone fusion.

In the present study, patients in group B showed a fusion rate of $29.3 \%, 53.4 \%$, and $91.4 \%$ at 3 months, 6 months, and one year after single-level ACDF, respectively, values that are significantly higher than the corresponding rates in group A $(11.8 \%, 31.4 \%$, and $76.5 \%)$. Similarly, patients treated with double-level ACDF in group $\mathrm{B}$ also had a higher fusion rate than patients in group $\mathrm{A}$ at 3 months, 6 months, and one year after the operation. Our results also revealed significantly greater cage subsidence after single- and double-level ACDF in group A $(1.8 \pm 0.7 \mathrm{~mm}$ and $2.9 \pm 1.4 \mathrm{~mm}$, respectively) than in group B $(1.5 \pm 0.5 \mathrm{~mm}$ and $2.3 \pm 0.8 \mathrm{~mm})$. The cage subsidence rate was reduced to $8.6 \%$ and $16.9 \%$ after single- and double-level ACDF, respectively, in group B. Although there were no significant differences in clinical outcomes or the fusion rate between the two groups at the final follow-up, it is crucial to improve the early fusion rate and reduce postoperative subsidence in ACDF. The fusion rate, fusion time, and extent of subsidence are usually used as critical indexes to evaluate the efficacy of a surgical technique [26-29]. Early fusion can also reduce the frequency of follow-up imaging examinations and increase the confidence of spinal surgeons performing this surgical technique. At present, there are still a number of studies revealing that postoperative subsidence is related to poor clinical outcomes [28-31]. Igarashi et al. [31] proposed that cage subsidence must be avoided in ACDF since it is often the cause of cervical foraminal stenosis and cage displacement.

During the operation to harvest the bone dust, saline was not used to cool the high-speed burr in our study. Park et al. [10] and Shad et al. [19] have confirmed that the use of high-speed burr without cooling in ACDF does not increase the risk of surgical complications. The related complications were also not occurred in our study. A small amount of blood seeping from the intervertebral space can reduce the temperature of the high-speed burr. Intermittent high-speed burr use during surgery can also avoid spinal cord injury caused by high temperatures from long-time driving of the high-speed burr.

The present study has several limitations. First, this study is based on a single-center, retrospective analysis, and the number of cases is small. A multicenter prospective study is required to confirm the current conclusion. Second, this study only included patients who underwent single- or double-level ACDF. Third, although both groups of patients were operated on by the same surgeon, the period of the operation was different between the two groups, which may influence the results of the study.

\section{Conclusions}

In this study, we compared two methods of using local bone as a cage-filling material in ACDF. We found that satisfactory clinical outcomes can be obtained in patients treated with single- or double-level ACDF using a 
mixture of bone dust and morselized bone or morselized bone alone to fill the n-HA/PA66 cage. This result indicates that local bone grafts with an n-HA/PA66 cage is a safe alternative to iliac bone grafts in ACDF. However, an n-HA/PA66 cage filled with a mixture of bone dust and morselized bone is more beneficial for achieving earlier bone fusion and reducing subsidence. The method of harvesting bone dust is convenient and safe and does not increase the risk of surgical complications.

\begin{abstract}
Abbreviations
ACDF: Anterior cervical discectomy and fusion; PEEK: Polyetheretherketone; n-HA/PA66: Nanohydroxyapatite/polyamide66; ACF: Anterior cervical fusion; CT: Computed tomography; MRI: Magnetic resonance imaging; NDI: Neck Disability Index; VAS: Visual analog scale; FSH: Fusion segmental height; SSA: Segmental sagittal alignment; DBM: Demineralized bone matrix; BMP: Bone matrix protein; TMC: Titanium mesh cage
\end{abstract}

\section{Acknowledgements}

Not applicable.

\section{Authors' contributions}

MF, XSC and ZDJ conceived and designed the study. TQ, TC acquired the data. MF, XSC, ZDJ, LYH and WQ analyzed and interpreted the data. MF, LYH and XSC drafted the manuscript. WQ and ZDJ critically revised the manuscript. All authors have read and approved the final version of the manuscript and affirm that the work has not been submitted or published elsewhere, in whole or in part.

\section{Funding}

No funding was received.

\section{Availability of data and materials}

Data will be available upon request to the first author, MF.

\section{Declarations}

\section{Ethics approval and consent to participate}

The protocol for the present study was approved by the Ethics Committee of the Affiliated Hospital of Southwest Medical University. Informed consent was obtained from all subjects.

\section{Consent for publication}

Not applicable.

\section{Competing interests}

The authors declare that they have no competing interests.

Received: 25 March 2021 Accepted: 20 May 2021

Published online: 02 June 2021

\section{References}

1. Smith GW, Robinson RA. The treatment of certain cervical-spine disorders by anterior removal of the intervertebral disc and interbody fusion. J Bone Joint Surg Am. 1958;40-A:607-624.

2. Jacobs W, Willems PC, van Limbeek J, Bartels R, Pavlov P, Anderson PG, Oner $C$. Single or double-level anterior interbody fusion techniques for cervical degenerative disc disease. Cochrane Database Syst Rev. 2011;(1): CD004958. https://doi.org/10.1002/14651858.CD004958.pub2.

3. Yue WM, Brodner W, Highland TR. Long-term results after anterior cervical discectomy and fusion with allograft and plating. A 5- to 11-year radiologic and clinical follow-up study. Spine. 2005;30:2138-2144.

4. Stark JR, Hsieh J, Waller D. Bone graft substitutes in single- or double-level anterior cervical discectomy and fusion: a systematic review. Spine (Phila Pa 1976). 2019;44(10):E618-28.
5. Silber JS, Anderson DG, Daffner SD, et al. Donor site morbidity after anterior iliac crest bone harvest for singlelevel anterior cervical discectomy and fusion. Spine (Phila Pa 1976) 2003;28:134-9.

6. Maharaj MM, Phan K, Mobbs RJ. Anterior cervical discectomy and fusion (ACDF) autograft versus graft substitutes: what do patients prefer?-A clinical study. J Spine Surg. 2016;2(2):105-110.

7. Samartzis D, Shen FH, Goldberg EJ, et al. Is autograft the old standard in achieving radiographic fusion in one-level anterior cervical discectomy and fusion with rigid anterior plate fixation? Spine (Phila Pa 1976) 2005;30:1756-61.

8. Hu B, Yang X, Hu Y, et al. The n-HA/PA66 cage versus the PEEK cage in anterior cervical fusion with single-level discectomy during 7 years of follow-up. World Neurosurg. 2019;123:e678-84.

9. Liu JM, Xiong X, Peng AF, et al. A comparison of local bone graft with PEEK cage versus iliac bone graft used in anterior cervical discectomy and fusion. Clin Neurol Neurosurg. 2017;155:30-35.

10. Park $\mathrm{S}$, Lee $\mathrm{DH}$, Hwang $\mathrm{S}$, et al. Feasibility of local bone dust as a graft material in anterior cervical discectomy and fusion. J Neurosurg Spine. 2019; 31:480-5.

11. Hu B, Wang L, Song $Y$, et al. A comparison of long-term outcomes of nanohydroxyapatite/polyamide-66 cage and titanium mesh cage in anterior cervical corpectomy and fusion: a clinical follow-up study of least 8 years. Clin Neurol Neurosurg. 2019;176:25-9.

12. Lee JH, Lee JH, Park JW, Lee HS. Fusion rates of a morselized local bone graft in polyetheretherketone cages in posterior lumbar interbody fusion by quantitative analysis using consecutive three-dimensional computed tomography scans. Spine J. 2011;11(7):647-653.

13. Kellgren JH, LAWRENCE JS. Radiological assessment of osteo-arthrosis. Ann Rheum Dis. 1957;16(4):494-502.

14. J.W. Brantigan, A.D. Steffee, A carbon fiber implant to aid interbody lumbar fusion.Two-year clinical results in the first 26 patients, Spine 18 (14) (1993) 2106-2107.

15. Papavero L, Zwönitzer R, Burkard I, Klose K, Herrmann HD. A composite bone graft substitute for anterior cervical fusion: assessment of osseointegration by quantitative computed tomography. Spine (Phila Pa 1976). 2002;27(10):1037-1043.

16. Min WK, Bae JS, Park BC, Jeon IH, Jin HK, Son MJ, et al: Proliferation and osteoblastic differentiation of bone marrow stem cells: comparison of vertebral body and iliac crest. Eur Spine J 19:1753-1760, 2010.

17. Boakye M, Mummaneni PV, Garrett M, Rodts G, Haid R. Anterior cervical discectomy and fusion involving a polyetheretherketone spacer and bone morphogenetic protein. J Neurosurg Spine. 2005;2(5):521-525.

18. Jacobs W, Willems PC, Kruyt M, et al. Systematic review of anterio interbody fusion techniques for single- and double-level cervical degenerative disc disease. Spine (Phila Pa 1976). 2011;36(14):E950-E960.

19. Street M, Gao R, Martis W, Munro J, Musson D, Cornish J, Ferguson J. The efficacy of local autologous bone dust: a systematic review. Spine Deform. 2017:5(4):231-7.

20. Patel W, Estes SM, Naar EM, Lindley EM, Burger E. Histologic evaluation of high speed burr shavings collected during spinal decompression surgery. Orthopedics. 2009;32(1):23.

21. Eder C, Chavanne A, Meissner J, Bretschneider W, Tuschel A, Becker P, Ogon M. Autografts for spinal fusion: osteogenic potential of laminectomy bone chips and bone shavings collected via high speed drill. Eur Spine J. 2011; 20(11):1791-5

22. Shad A, Leach JC, Teddy PJ, Cadoux-Hudson TA. Use of the Solis cage and local autologous bone graft for anterior cervical discectomy and fusion: early technical experience. J Neurosurg Spine. 2005;2(2):116-122.

23. Wang XT, Zhou CL, Yan JL, Yan X, Xie HX, Sun CL. The fate of donor osteocytes in fine particulate bone powders during repair of bone defects in experimental rats. Acta Histochem. 2012;114(3):192-198.

24. Phemister DB. The classic: repair of bone in the presence of aseptic necrosis resulting from fractures, transplantations, and vascular obstruction. Clin Orthop Relat Res. 2008;466:1021-33.

25. Ye S, Seo KB, Park BH, Song KJ, Kim JR, Jang KY, Chae YJ, Lee KB. Comparison of the osteogenic potential of bone dust and iliac bone chip. Spine J. 2013;13(11):1659-66.

26. Song K, Taghavi CE, Hsu MS, Lee KB, Kim GH, Song JH. Plate augmentation in anterior cervical discectomy and fusion with cage for degenerative cervical spinal disorders. Eur Spine J. 2010;19(10):1677-1683.

27. Choi MK, Kim SB, Park CK, Lee SH, Jo DJ. Relation of deep paraspinal muscles' cross-sectional area of the cervical spine and bone union in 
anterior cervical decompression and fusion: a retrospective study. World Neurosurg. 2016;96:91-100.

28. Obermueller T, Wagner A, Kogler $L$, et al. Radiographic measurements of cervical alignment, fusion and subsidence after ACDF surgery and their impact on clinical outcome. Acta Neurochir (Wien). 2020;162(1):89-99.

29. Oliver JD, Goncalves S, Kerezoudis P, et al. Comparison of outcomes for anterior cervical discectomy and fusion with and without anterior plate fixation: a systematic review and meta-analysis. Spine (Phila Pa 1976). 2018; 43(7):E413-22

30. Noordhoek I, Koning MT, Jacobs WCH, Vleggeert-Lankamp CLA. Incidence and clinical relevance of cage subsidence in anterior cervical discectomy and fusion: a systematic review. Acta Neurochir (Wien). 2018;160(4):873-880.

31. Igarashi $\mathrm{H}$, Hoshino $\mathrm{M}$, Omori $\mathrm{K}$, et al. Factors influencing interbody cage subsidence following anterior cervical discectomy and fusion. Clin Spine Surg. 2019;32(7):297-302

\section{Publisher's Note}

Springer Nature remains neutral with regard to jurisdictional claims in published maps and institutional affiliations.

Ready to submit your research? Choose BMC and benefit from:

- fast, convenient online submission

- thorough peer review by experienced researchers in your field

- rapid publication on acceptance

- support for research data, including large and complex data types

- gold Open Access which fosters wider collaboration and increased citations

- maximum visibility for your research: over $100 \mathrm{M}$ website views per year

At BMC, research is always in progress.

Learn more biomedcentral.com/submissions 